\title{
Simultaneous detection of feline parvovirus and feline bocavirus using SYBR Green I-based duplex real-time polymerase chain reaction
}

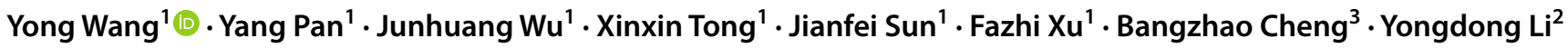

Received: 8 May 2021 / Accepted: 28 July 2021 / Published online: 6 August 2021

(c) King Abdulaziz City for Science and Technology 2021

\begin{abstract}
Since both feline parvovirus (FPV) and feline bocavirus (FBoV) can cause diarrhea in cats, it is difficult to distinguish them clinically. This study aimed to develop a SYBR Green I-based duplex real-time polymerase chain reaction (PCR) assay for distinguishing FPV and FBoV-1 on the basis of the melting temperature of the PCR product. A total of 132 fecal samples from different domestic and feral cats were collected, and the results of SYBR Green I-based duplex real-time PCR assay were compared with those of the traditional PCR assay for a comprehensive evaluation. The melting temperatures were found to be $86^{\circ} \mathrm{C}$ and $77.5^{\circ} \mathrm{C}$ for FBoV-1 and FPV, respectively, and no specific melting peaks for other non-targeted feline viruses were observed. The data obtained from this assay had a good linear relationship; the detection limits of FPV and FBoV-1 were $2.907 \times 10^{1}$ copies $/ \mu \mathrm{L}$ and $3.836 \times 10^{1}$ copies $/ \mu \mathrm{L}$, respectively. In addition, the experiment exhibited high reproducibility. The positive detection rates of the SYBR Green I-based duplex real-time PCR assay for FPV and FBoV-1 were $16.67 \%$ (22/132) and 6.82\% (9/132), respectively, and the positive detection rate for co-infection with FPV and FBoV-1 was $3.03 \%$ (4/132). This result was much more sensitive than that of the traditional PCR method. Thus, the developed SYBR Green I-based assay is a sensitive, rapid, specific, and reliable method for the clinical diagnosis of FPV and FBoV-1 and can provide technical support for the simultaneous detection of co-infection with these viruses in the future.
\end{abstract}

Keywords Feline bocavirus $\cdot$ Feline parvovirus $\cdot$ Simultaneous detection $\cdot$ Duplex real-time polymerase chain reaction

\section{Introduction}

Parvoviridae are mainly divided into two subfamilies: Parvovirinae and Densovirinae (Kailasan et al. 2015). Feline parvovirus (FPV) belongs to the Protoparvovirus genus of the Parvovirinae subfamily (Kailasan et al. 2015). FPV is the pathogen of feline panleukopenia, which is a highly contagious disease that primarily causes high fever, diarrhea,

Yong Wang and Yang Pan contributed equally to this work and considered to be the co-first authors.

Yongdong $\mathrm{Li}$

liyd0551@126.com

1 College of Animal Science and Technology, Anhui Agricultural University, Hefei 230036, PR China

2 Municipal Key Laboratory of Virology, Ningbo Municipal Center for Disease Control and Prevention, Ningbo 315010, PR China

3 Prevention and Control Center for Animal Disease of Xuan Cheng City, Xuancheng 242000, PR China and other clinical symptoms (Barrs 2019). The virus is a positive, single-stranded, non-segmental and linear DNA virus. It is approximately $20-24 \mathrm{~nm}$ in diameter, the full genome of FPV is approximately 5000 nucleotide long (Pfankuche et al. 2018). FPV can infect both domestic and wild cats and is extremely harmful to them. Bocavirus belongs to the Bocaparvovirus genus of the Parvovirinae subfamily. Common bocaviruses include human bocavirus, bovine bocavirus, porcine bocavirus, canine bocavirus, and feline bocavirus (FBoV). FBoV is a single-stranded, nonenveloped, linear DNA virus with an icosahedral appearance and a diameter of approximately 25-26 nm (Zhai et al. 2017; Cotmore et al. 2014). The genome of FBoV is approximately 5500 nucleotides in length and has three open reading frames (ORFs), namely $O R F 1, O R F 2$, and $O R F 3$. Among them, ORF1 encodes the nonstructural protein NS1, ORF2 encodes the viral nucleocapsid protein $V P 1 / V P 2$, and $O R F 3$ encodes the nuclear phosphoprotein $N P 1$, respectively (Zhai et al. 2017; Amimo et al. 2017). Owing to the uniqueness of $N P 1$ protein, bocavirus is significantly different from other members of the Parvoviridae family (Zou et al. 2016; Sun 
et al. 2013). FBoV can also cause diarrhea, which is possibly harmful to cats.

FPV was isolated in 1965 for the first time (Johnson et al. 1967). In 1977, American scholars Eugster and Nair found a variant of the FPV virus in fecal samples from a dog with diarrhea and named it canine parvovirus (CPV-2) (Wang et al. 2016). Subsequently, the virus was reported in several countries, such as Canada, France, Japan, and other countries. FPV is highly homologous to CPV-2 (McEndaffer et al. 2017), which is significantly different from the previously identified CPV. CPV-2 does not infect cats; however, three later discovered antigenic variants (CPV-2a, CPV-2b, and CPV-2c) were found to infect cats (Garigliany et al. 2016; Wang et al. 2016; Truyen and Parrish 1992). The mutation rate of CPV is higher than that of FPV. FBoV contains three genotypes: FBoV-1, FBoV-2, and FBoV-3. In 2012, a new bocavirus was first found in Hong Kong in the fecal, nasal, and serum samples of domestic cats and named FBoV-1 (Lau et al. 2012). Thereafter, FBoV-2 and FBoV-3 were discovered, in succession, in the fecal samples of cats using high-throughput sequencing technology (Zhang et al. 2014; Ng et al. 2014). Recently, researchers successfully isolated $\mathrm{FBoV}$ for the first time by collecting and analyzing the fecal samples from cats suffering from severe enteritis in mainland China (Liu et al. 2018). FBoV has been found in various countries, including Belgium, Japan, the United States (Ng et al. 2014; Takano et al. 2016; Zhang et al. 2014; Yi et al. 2018b). However, in China, the prevalence of FBoV remains unclear, and the genotype distribution is not well understood. Co-infection of the two viruses exacerbated the deterioration of the cat's health (Piewbang et al. 2019). Moreover, co-infection increases the difficulty of treatment. So, there is an urgent need for a rapid, sensitive and reliable assay that can simultaneously detect the two viruses.

Rapid, sensitive, and reliable detection technologies play an extremely crucial role in the prevention and control of diseases. In contrast to various traditional diagnostic methods, such as the enzyme-linked immunosorbent assay (ELISA) and immuno-peroxidase monolayer assay (Okiro et al. 2019), real-time quantitative polymerase chain reaction (qPCR) is more flexible, rapid, and has good efficacy in terms of sensitivity, specificity, and reliability. A number of existing studies have used qPCR to detect FPV or FBoV (Yi et al. 2018b; Sun et al. 2019); however, to our best knowledge, there is no robust method to simultaneously detect the co-infection of FPV and FBoV-1. In this study, a SYBR Green I-based Duplex Real-time PCR assay was established to simultaneously detect FPV and FBoV in cat fecal samples, and the feasibility of applying this experimental model was evaluated. This method may be able to provide a certain reference value for the clinical diagnosis of other viral mixed infections, which will be a major progress in veterinary clinical diagnosis technology.

\section{Materials and methods}

\section{Fecal samples collection}

From June 2019 to September 2020, a total of 132 domestic cat fecal samples were collected from Shanghai, Hefei, Nanjing, Maanshan, and other places in China, including 92 samples from cats with diarrhea and 40 samples from cats without diarrhea. After confirmation, the tissue samples were homogenized, diluted with phosphate-buffered saline at a ratio of $1: 10$, and then centrifuged at $8000 \times g$ for $3 \mathrm{~min}$. The supernatant was used for nucleic acid extraction or stored at $-40{ }^{\circ} \mathrm{C}$ for subsequent use; All the other viral groups used extracted nucleic acid from clinical samples stored at $-40^{\circ} \mathrm{C}$ in our laboratory that had previously been identified, including feline astrovirus (FAstV), feline calicivirus (FCV), feline herpesvirus (FHV), and feline coronavirus $(\mathrm{FCoV})$.

\section{Viral DNA extraction}

All nucleotides were extracted using the TIANamp Virus DNA/RNA Kit (Tiangen, Beijing, China); according to the manufacturer's instructions. The samples were stored at -20 ${ }^{\circ} \mathrm{C}$ until using. All RNA viruses were reverse transcribed into cDNA using the Prime Script ${ }^{\mathrm{TM}}$ RT Reagent Kit with gDNA Eraser (Takara, Dalian, China), and operated according to the manufacturer's instructions, and stored at $-20^{\circ} \mathrm{C}$ until use.

\section{Primer design}

The nucleotide sequences for FPV and FBoV-1 were downloaded from GenBank. The MegAlign software was used to compare the nucleotide sequences of FPV and FBoV-1 to obtain a highly conserved sequence. A pair of primers for constructing the recombinant plasmid and a pair of specific primers for detection were designed using the Primer Premier 5.0 software (Table 1). The location and size of the specific primers for each target gene and the length of each amplified fragment are shown in Table 1 . The primers were synthesized by a commercial corporation (General Biological System [Anhui] Co., Ltd., Chuzhou, China).

\section{Preparation of standard plasmids}

The extracted DNA was used as the template, and the target fragments of FPV and FBoV-1 were amplified using the above-mentioned primers (Table 1). The positive amplification products were recovered and purified using the TIANgel Midi purification Kit (Tiangen) according to the 
Table 1 Primers used in this study

\begin{tabular}{lllll}
\hline Primer name & Sequences $\left(5^{\prime}-3^{\prime}\right)$ & $\begin{array}{l}\text { Melting tem- } \\
\text { perature }\left({ }^{\circ} \mathrm{C}\right)\end{array}$ & $\begin{array}{l}\text { Product } \\
\text { size }(\mathrm{bp})\end{array}$ & Targeted gene \\
\hline $\begin{array}{l}\text { FPV-F } \\
\text { FPV-R }\end{array}$ & $\begin{array}{l}\text { ATCTGCTACTCAGCCACC } \\
\text { GGTGTTCTCCTGTTGTAGT }\end{array}$ & 50 & 720 & VP1 \\
FBoV-F & CGAGGAAAAGACACCACGAC & 58 & 642 & NS1 \\
FBoV-R & CTTCCATGGCGACCGCT & & & \multirow{2}{*}{ VP1 } \\
FPV-SYBR-F & CAACCATACCAACTCCAT & 60 & 177 & \multirow{2}{*}{ NS1 } \\
FPV-SYBR-R & ATTCATCACCTGTTCTTAGTA & & 121 \\
FBoV-SYBR-F & AGTGCCGAGCAAGAAGGG & 60 & & \\
FBoV-SYBR-R & CGAAGCAGTGGAGCGTGA & &
\end{tabular}

manufacturer's instructions. Then, it was verified with electrophoresis on a $1 \%$ agarose gel. The purified products were cloned into the pMD19-T vector (Takara) and verified using commercial sequencing [General Biological System (Anhui) Co., Ltd.]. The recombinant plasmids were named pMD19FPV and pMD19-FBoV and quantified by measuring the optical density at $260 \mathrm{~nm}\left(\mathrm{OD}_{\mathbf{2 6 0}}\right)$ and $\mathrm{OD}_{\mathbf{2 8 0}}$ using a Nanodrop 2000 spectrophotometer (Thermo Fisher Scientific, Waltham, MA, USA). The copy number of each plasmid was calculated according to the following formula: amount (copies $/ \mu \mathrm{L})=\left(6.02 \times 10^{23}\right) \times\left(\right.$ concentration in $\left.\mathrm{ng} \times 10^{-9}\right) /($ plasmid length $\times 660 \mathrm{Da} / \mathrm{bp})(\mathrm{Yu}$ et al. 2020). Concentrations of the recombinant plasmids pMD19-FPV and pMD19-FBoV were $2.907 \times 10^{11} \mathrm{ng} / \mu \mathrm{L}$ and $3.836 \times 10^{11} \mathrm{ng} / \mu \mathrm{L}$, respectively. The plasmids were continuously diluted tenfold for subsequent amplification and stored at $-40{ }^{\circ} \mathrm{C}$ until use.

\section{Optimization of the FPV/FBoV-1 duplex SYBR Green real-time PCR assay}

The parameters of FPV/FBoV-1 duplex SYBR Green realtime PCR assay were optimized with plasmid template of $10^{8}$ copies/ $\mu \mathrm{L}$ to obtain the best experimental results, including the PCR program, primer concentration, and annealing temperature (Supplementary Table S1).

\section{Singular and duplex real-time qPCR}

After optimization of the reaction parameters, both the singular qPCR and duplex real-time qPCR assays were performed on a CFX96 Real-Time PCR Detection System (BioRad, Hercules, CA, USA). For the singular qPCR assay for FPV, the reaction volume was $20 \mu \mathrm{L}$, comprising $0.6 \mu \mathrm{L}$ each of forward and reverse primers, $10 \mu \mathrm{L}$ of $2 \times$ SuperReal Premix Plus (Tiangen), $1 \mu \mathrm{L}$ of DNA template, and RNase-free $\mathrm{H}_{2} \mathrm{O}$ (to make up final volume). The singular qPCR assay for FBoV-1 had the same reaction components as the reaction for FPV. The reaction volume for the duplex real-time qPCR assay was $40 \mu \mathrm{L}$, containing $0.2 \mu \mathrm{L}$ of each primer for FBoV-1, $0.8 \mu \mathrm{L}$ of each primer for FPV, $1 \mu \mathrm{L}$ of
FPV DNA template, $1 \mu \mathrm{L}$ of FBoV-1 DNA template, and $20 \mu \mathrm{L}$ of $2 \times$ SuperReal Premix Plus (Tiangen). RNase-free $\mathrm{H}_{2} \mathrm{O}$ was added to make up final volume. The reaction conditions for both singular and duplex qPCR were as follows: $15 \mathrm{~min}$ at $95^{\circ} \mathrm{C}$, followed by 40 cycles of $10 \mathrm{~s}$ at $95^{\circ} \mathrm{C}$ and $30 \mathrm{~s}$ at $60{ }^{\circ} \mathrm{C}$. The annealing/extension temperature was then optimized. The reaction without template and the negative reference samples were used as negative controls.

\section{Establishment of standard curves}

In the real-time qPCR assay, the recombinant plasmid DNA was continuously diluted tenfold from $10^{8}$ copies $/ \mu \mathrm{L}$ to $10^{1}$ copies $/ \mu \mathrm{L}$. The logarithm of the initial template number was plotted on the x-axis, and the cycle threshold was plotted on the $\mathrm{y}$-axis to establish a standard curve.

\section{Assessment of sensitivity, specificity and reproducibility}

The recombinant plasmid was successively diluted from $10^{8}$ copies $/ \mu \mathrm{L}$ to $10^{1}$ copies $/ \mu \mathrm{L}$ as a positive control to determine the minimum detection limits of FPV and FBoV-1. The sensitivity of single and duplex qPCR detection of the recombinant plasmid was compared to that of the conventional PCR assay. Specificity for the detection of FPV and FBoV-1 was evaluated with duplex real-time qPCR using the above-mentioned DNA or RNA virus samples as templates and RNase-free $\mathrm{H}_{2} \mathrm{O}$ as the negative control. Three plasmid templates with different concentrations $\left(10^{7}, 10^{5}\right.$, and $10^{3}$ copies $/ \mu \mathrm{L}$ ) were selected to simultaneously carry out three parallel tests under the same amplification conditions. The coefficient of variation $(\mathrm{CV})$ was calculated to evaluate the reproducibility of the inter/intra-assay values.

\section{Evaluation of clinical samples with real-time and conventional PCR assays}

DNA was extracted from 132 clinical samples (fecals) and detected using conventional and real-time PCR. The positive

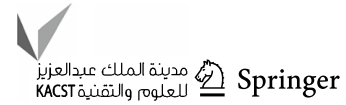


samples were all verified with $1 \%$ agarose gel electrophoresis, and the positive samples were sequenced again to confirm the reliability.

\section{Results}

\section{Construction of FPV and FBoV-1 standard curves}

Using standard plasmids from $2.907 \times 10^{8}$ copies $/ \mu \mathrm{L}$ to $2.907 \times 10^{1}$ copies $/ \mu \mathrm{L}$ as the standard templates for FPV, a linear standard curve was plotted with the logarithm of the initial template number as the $\mathrm{x}$-axis and the cycle threshold as the $y$-axis. The standard curve was defined as $y=-3.226 x+36.155$, with an $R^{2}$ value (square of the correlation coefficient) of 0.999 (Fig. 1a). A linear standard curve was plotted with viral genomes from $3.836 \times 10^{8}$ copies $/ \mu \mathrm{L}$ to $3.836 \times 10^{1}$ copies $/ \mu \mathrm{L}$ as the standard templates for FBoV1 ; the curve was defined as $y=-3.295 x+38.133$, with an $R^{2}$ value of 0.998 (Fig. 1b).

\section{Optimization of duplex qPCR assay}

To obtain stable fluorescence signal, the subsequent optimization experiments showed that the optimal amount of primers for FPV and FBoV-1 is $0.8 \mu \mathrm{L}$ and $0.2 \mu \mathrm{L}$, respectively. And the optimal temperature is $60{ }^{\circ} \mathrm{C}$. The $\mathrm{CV}$ values obtained under these conditions were minimal, so the subsequent duplex real-time PCR was performed according to these reaction conditions. After the primer concentration and annealing temperature were optimized, the fluorescence signals of FPV and FBoV-1 were detected with singular qPCR. The lowest cycle threshold was recorded and a melting curve was established. Melting curve analysis revealed
Fig. 1 Standard curve analysis. a Standard curve of the SYBR Green I-based duplex real-time qPCR assay for FPV (concentrations ranged from $2.907 \times 10^{8}$ copies $/ \mu \mathrm{L}$ to $2.907 \times 10^{1}$ copies/ $\mu \mathrm{L} ; y=-3.226 x+36.155$; $\left.R^{2}=0.999\right)$. b Standard curve of the SYBR Green I-based duplex real-time qPCR assay for FBoV-1 (concentrations ranged from $3.836 \times 10^{8}$ copies $/ \mu \mathrm{L}$ to $3.836 \times 10^{1}$ copies $/ \mu \mathrm{L} ; y=-$ $\left.3.295 x+38.133 ; R^{2}=0.998\right)$
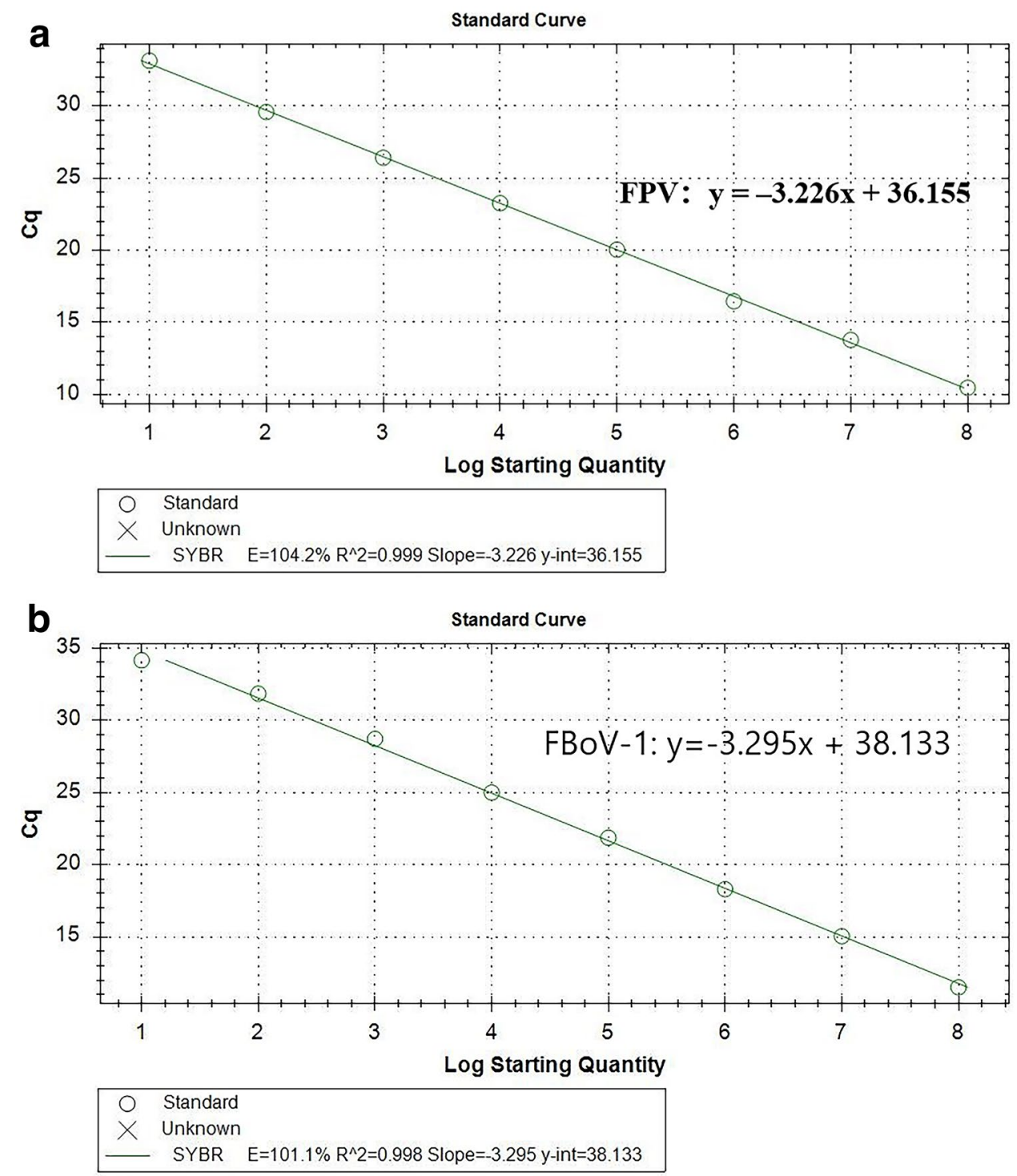
that the melting temperature of FPV was $77.5^{\circ} \mathrm{C}$ and that of FBoV-1 was $86^{\circ} \mathrm{C}$ (Fig. 2a and b). The results of the duplex qPCR assay showed that FPV and FBoV-1 could be easily distinguished based on their different melting temperatures (Fig. 3).

\section{Sensitivity of duplex qPCR assay}

Sensitivity was assessed using the standard plasmids of FPV or/and FBoV-1 as templates and a tenfold dilution with RNase-free $\mathrm{H}_{2} \mathrm{O}\left(2.907 \times 10^{8}\right.$ copies $/ \mu \mathrm{L}$ to $2.907 \times 10^{1}$ copies $/ \mu \mathrm{L}$ for FPV and $3.836 \times 10^{8}$ copies $/ \mu \mathrm{L}$ to $3.836 \times 10^{1}$ copies $/ \mu \mathrm{L}$ for FBoV-1) to determine the limit of detection. The detection limits were $2.907 \times 10^{1}$ copies $/ \mu \mathrm{L}$ and $3.836 \times 10^{1}$ copies $/ \mu \mathrm{L}$ for FPV and FBoV-1, respectively, and the Sensitivity of duplex qPCR is also $10^{1}$ copies $/ \mu \mathrm{L}$ (Fig. 4a, b and c).

\section{Specificity of duplex qPCR assay}

In the specificity assessment, a total of six viral genomes (FAstV, FCV, FHV, FCoV, FPV, and FBoV-1) were simultaneously detected, among which only FPV and FBoV-1 showed specific melting peaks $\left(77.5^{\circ} \mathrm{C}\right.$ for FPV and $86^{\circ} \mathrm{C}$ for FBoV-1; Fig. 5).

\section{Reproducibility of the duplex real-time qPCR assay}

To determine the reproducibility of the experiment, three parallel tests were carried out independently by three individuals using three different concentrations $\left(10^{7} \mathrm{cop}\right.$ ies $/ \mu \mathrm{L}, 10^{5}$ copies $/ \mu \mathrm{L}$, and $10^{3}$ copies $/ \mu \mathrm{L}$ ) of standard plasmids, and comparisons of the intra-assay and interassay CVs were made. The results showed that the intraassay CV was $0.81-1.32 \%$ for FPV and $0.15-0.89 \%$ for FBoV-1. The inter-assay CV was $1.35-1.54 \%$ for FPV and
Fig. 2 Melting curve analysis. a Melting curve of FPV $\left(\mathrm{Tm}=78 \pm 0.5^{\circ} \mathrm{C}\right)$. b Melting curve of FBoV-1 $(\mathrm{Tm}=86 \pm 0.5$ $\left.{ }^{\circ} \mathrm{C}\right)$. Tm, melting peak temperature
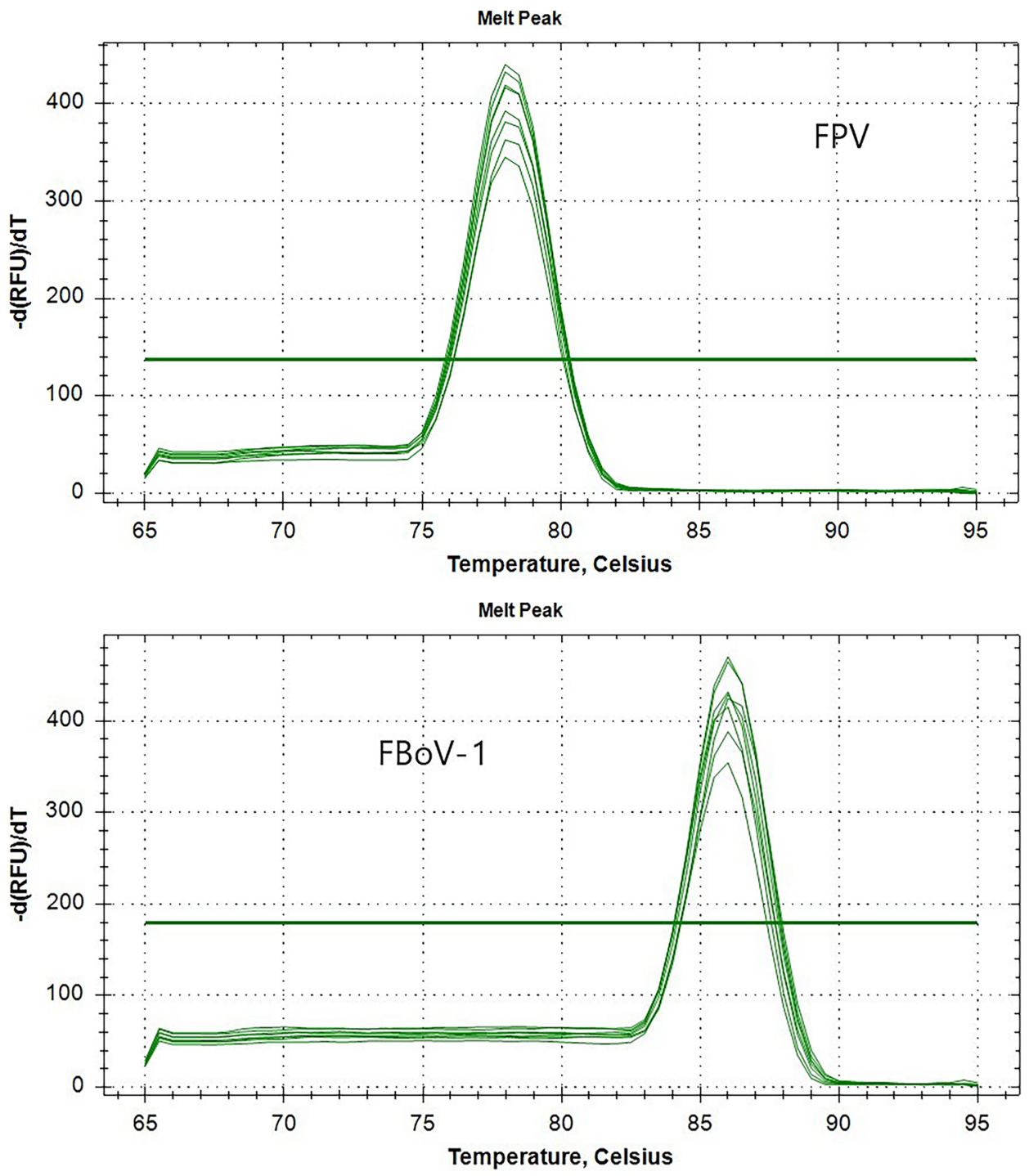
Fig. 3 Melting curve analysis of the SYBR Green I-based duplex real-time qPCR for FPV $\left(\mathrm{Tm}=77.5^{\circ} \mathrm{C}\right)$ and $\mathrm{FBoV}-1$ $\left(\mathrm{Tm}=86^{\circ} \mathrm{C}\right)$. Tm, melting peak temperature

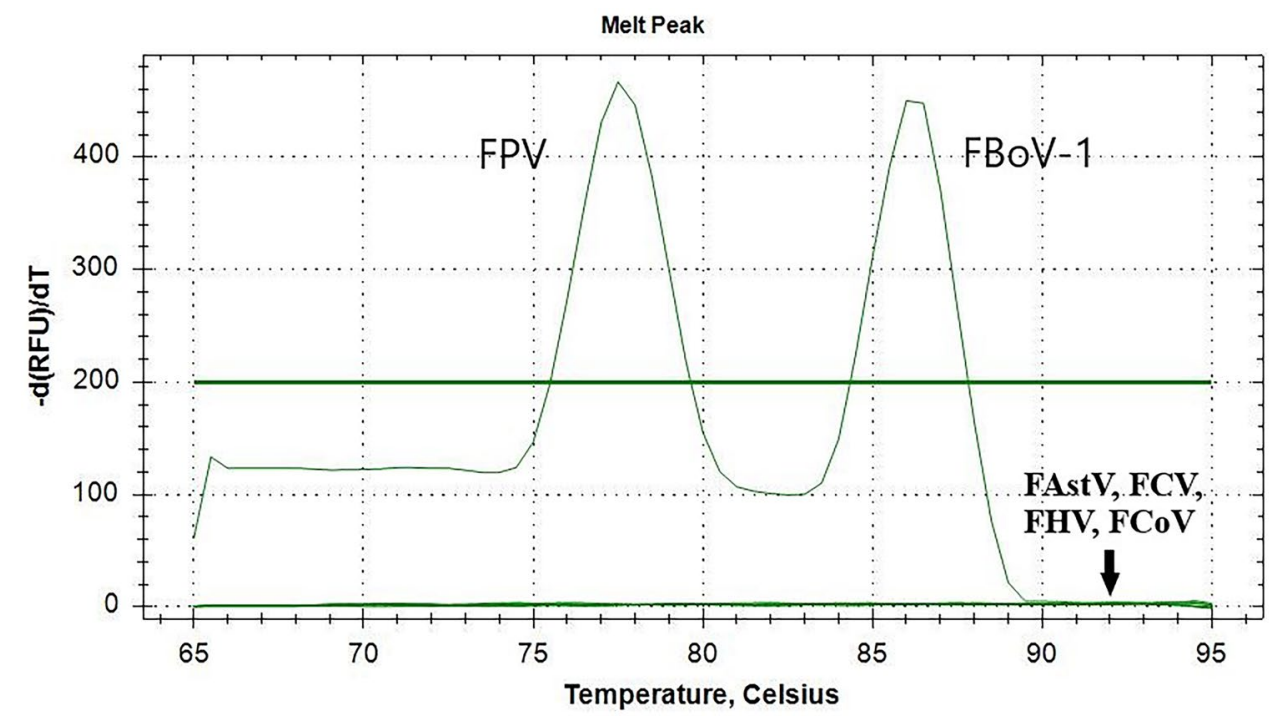

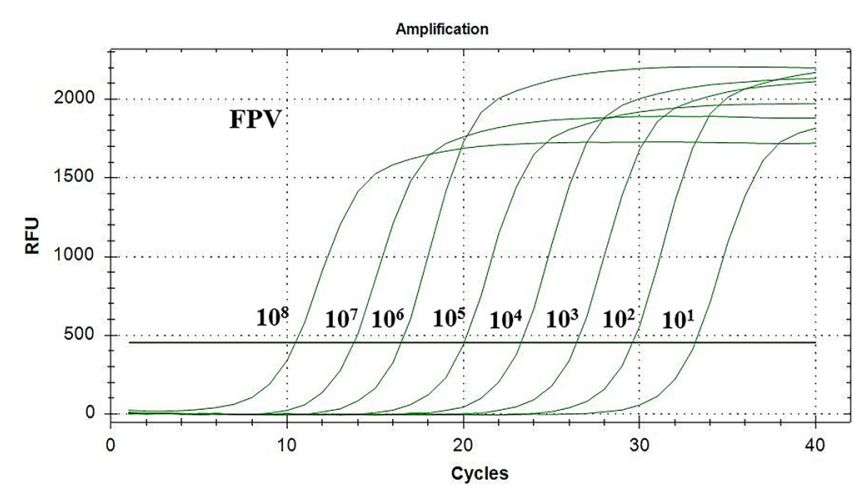

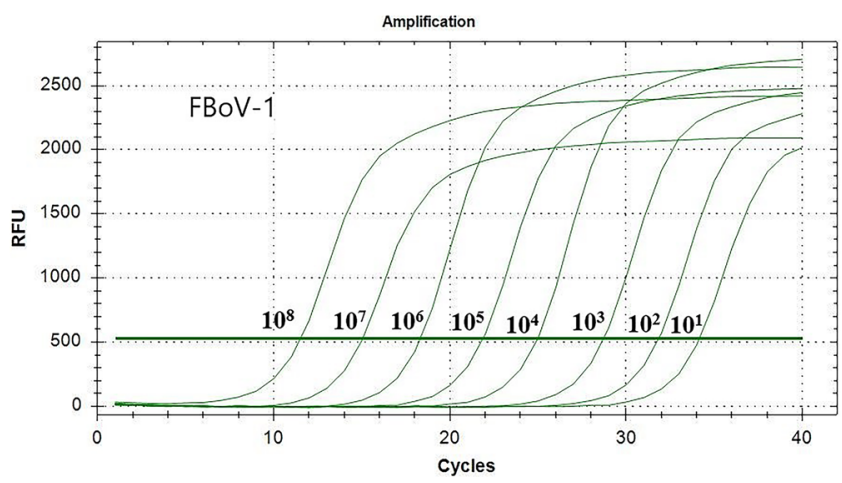

Fig. 4 Sensitivity analysis. a Amplification curve of the SYBR Green I-based duplex real-time qPCR assay of FPV. The lowest limit of detection of the assay was $2.907 \times 10^{1}$ copies/ $\mu \mathrm{L}$. b Amplification curve of the SYBR Green I-based duplex real-time qPCR assay of

$0.39-1.71 \%$ for FBoV-1 (Table 2). These results indicate that the duplex qPCR has the advantages of low variability and high reproducibility.

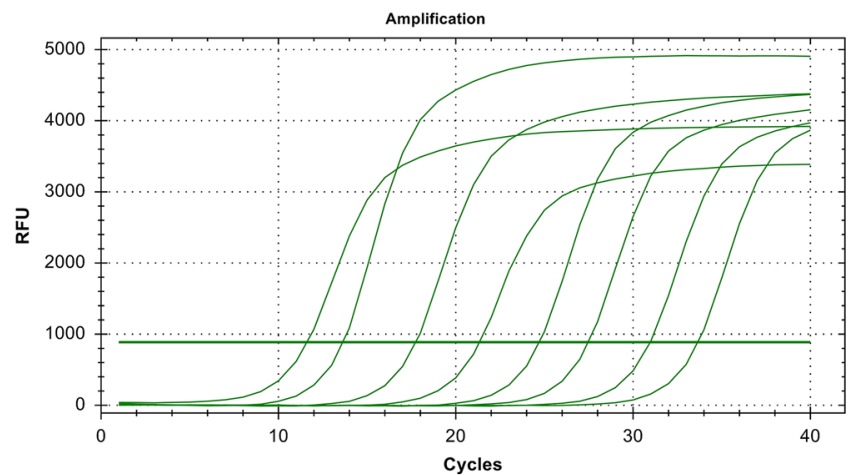

FBoV-1. The lowest limit of detection of the assay was $3.836 \times 10^{1}$ copies $/ \mu \mathrm{L}$. c Amplification curve of the SYBR Green I-based duplex real-time qPCR assay of FPV and FBoV-1. The lowest limit of detection of the assay was $10^{1}$ copies $/ \mu \mathrm{L}$

\section{Evaluation of the duplex real-time qPCR assay using clinical samples}

Fecal samples from 132 cats were collected for the 
Fig. 5 Specificity analysis. There are no specific curves of FAstV, FCV, FHV, FCoV, and RNase-free $\mathrm{H}_{2} \mathrm{O}$

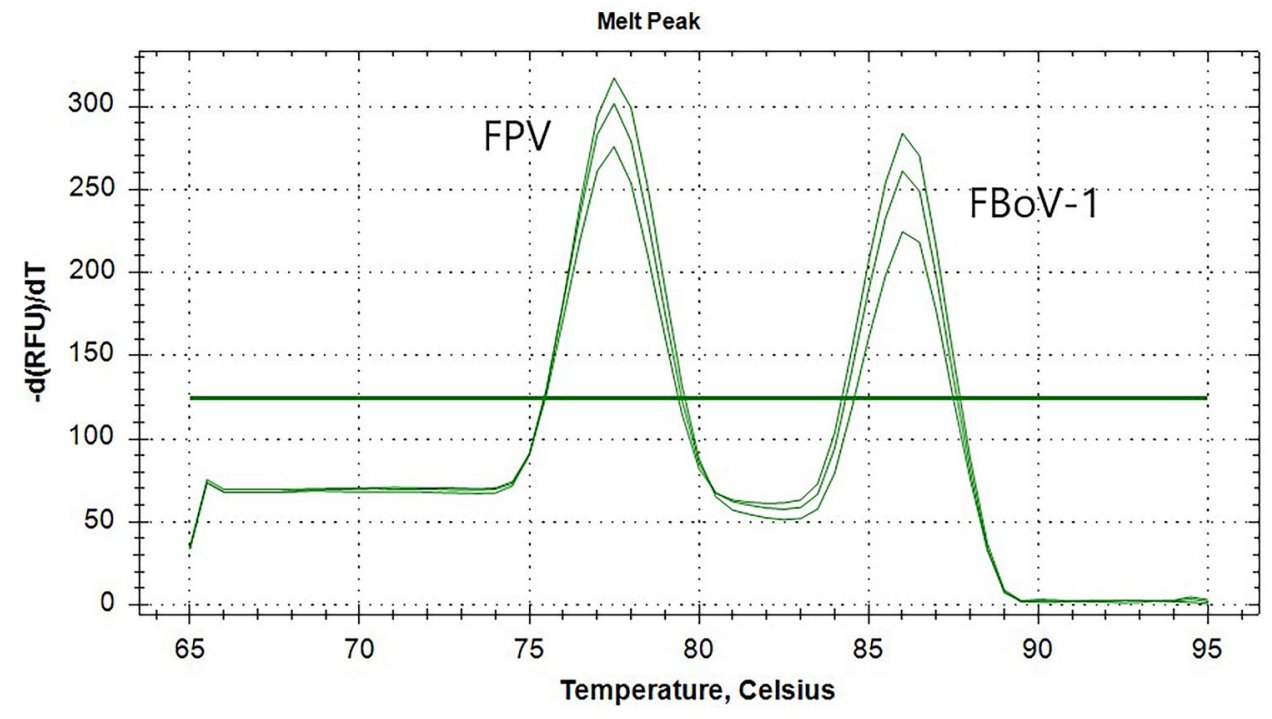

Table 2 Intra- and inter-assay CVs of FPV and FBoV-1

\begin{tabular}{|c|c|c|c|c|c|}
\hline & Category & $\begin{array}{l}\text { DNA standard } \\
\text { (copies } / \mu \mathrm{L})\end{array}$ & Mean $(\mathrm{Ct})$ & SD & $\mathrm{CV}(\%)$ \\
\hline \multirow{3}{*}{ FPV } & \multirow[t]{3}{*}{ Intra-assay } & $1 \times 10^{7}$ & 13.64 & 0.18 & 1.32 \\
\hline & & $1 \times 10^{5}$ & 20.47 & 0.17 & 0.81 \\
\hline & & $1 \times 10^{3}$ & 26.59 & 0.29 & 1.10 \\
\hline \multirow{9}{*}{ FBoV-1 } & \multirow[t]{3}{*}{ Inter-assay } & $1 \times 10^{7}$ & 13.46 & 0.20 & 1.50 \\
\hline & & $1 \times 10^{5}$ & 20.51 & 0.32 & 1.54 \\
\hline & & $1 \times 10^{3}$ & 26.62 & 0.36 & 1.35 \\
\hline & \multirow[t]{3}{*}{ Intra-assay } & $1 \times 10^{7}$ & 14.65 & 0.10 & 0.89 \\
\hline & & $1 \times 10^{5}$ & 21.47 & 0.16 & 0.72 \\
\hline & & $1 \times 10^{3}$ & 28.20 & 0.04 & 0.15 \\
\hline & \multirow[t]{3}{*}{ Inter-assay } & $1 \times 10^{7}$ & 14.50 & 0.23 & 1.60 \\
\hline & & $1 \times 10^{5}$ & 21.49 & 0.37 & 1.71 \\
\hline & & $1 \times 10^{3}$ & 28.24 & 0.11 & 0.39 \\
\hline
\end{tabular}

individual detection of FPV and FBoV-1 using real-time qPCR. The results showed that 22 samples were positive for FPV, and the detection rate was $16.67 \%$ (22/132). Nine samples were positive for FBoV-1, with a detection rate of $6.82 \%$ (9/132). Four samples were positive for FPV and FBoV-1 co-infection, and the positive detection rate for co-infection was $3.03 \%$ (4/132). The positive samples were sequenced again to determine the reliability of real-time qPCR. Single real-time qPCR and conventional PCR were also used to detect these samples; The results of the conventional PCR showed that 18 samples were positive for FPV, with a detection rate of $13.64 \%$ (18/132). Seven samples were positive for FBoV-1, with a detection rate of 5.30\% (7/132). The positive detection rate for co-infection with FPV and FBoV-1 was $1.52 \%$ (2/132). And the results of the single real-time qPCR were same as the duplex qPCR (Table 3). All the positive results were reliable by sequencing. Thus, the samples that tested positive using conventional PCR also tested positive using real-time qPCR.

\section{Discussion}

FPV is a common virus that causes diarrhea in cats and can be fatal in severe cases. FBoV is a newly discovered virus belonging to the same family of Parvoviridae as FPV. Several studies have shown that FBoV can cause diarrhea via concurrent infection with other viruses (Piewbang et al. 2019; Yi et al. 2018a; Lu et al. 2018). Recently, it was reported that the detection rate of FBoV in cats with diarrhea was as high as $33.3 \%$ in Northeast China (Niu et al. 2019; Yi et al. 2018b). In cats with diarrhea, co-infection with FPV and FBoV adds significant complications to proper clinical diagnosis and treatment. At present, there is
Table 3 Detection of FPV and FBoV-1 in clinical samples by conventional PCR (CPCR) and quantitative real-time PCR (qPCR)

\begin{tabular}{llllll}
\hline & Quantity & Results & & \\
\cline { 3 - 5 } & & FPV & FBoV-1 & FPV /FBoV-1 & Negative \\
\hline Duplex qPCR & 132 & $22(16.67 \%)$ & $9(6.82 \%)$ & $4(3.03 \%)$ & 105 \\
Single qPCR (FPV) & 132 & $22(16.67 \%)$ & 0 & 0 & 110 \\
Single qPCR (FBoV-1) & 132 & 0 & $9(6.82 \%)$ & 0 & 123 \\
cPCR & 132 & $18(13.64 \%)$ & $7(5.30 \%)$ & $2(1.52 \%)$ & 105 \\
\hline
\end{tabular}


no suitable detection method for the quantitative and simultaneous detection of FPV and FBoV in a sample. The lack of effective diagnostic methods is very disadvantageous to the epidemiological investigation and prevention and control of the diseases. Therefore, a reliable, sensitive, and rapid detection method is urgent needed to simultaneously detect FPV and $\mathrm{FBoV}$ in epidemiological and clinical diagnostic studies.

To date, a variety of laboratory detection methods, including loop-mediated isothermal amplification (LAMP) (Wong et al. 2018), TaqMan-based real-time PCR assay (Liu et al. 2019), ELISA (Wischhusen and Padilla 2017), SYBR Green duplex real-time qPCR assay, and immunohistochemical analysis (Hai et al. 2020), have been used to effectively detect viruses. Among them, LAMP does not require complicated equipment and provides visual experimental results; however, it is easy to show false positive due to the contamination of reagents, which will affect the experimental results. Immunohistochemical analysis and ELISA require a long operation time, and cannot be used to estimate the number of copies of viral DNA/cDNA. TaqMan-based real-time PCR assay has good specificity and sensitivity, but is not cost-effective. The SYBR Green duplex real-time qPCR assay is a widely used detection method with good specificity, sensitivity, highly reproducible, and cost-effective. Compared to the conventional PCR, the SYBR Green duplex real-time qPCR assay has more obvious advantages, such as simplicity, efficiency, and sensitivity, which enables high-throughput screening and quantification of viral vectors using only a small amount of virus. In this study, a SYBR Green duplex real-time qPCR method was established for the simultaneous detection of FPV and FBoV-1 in 132 fecal samples. The positive detection rates of FPV and FBoV-1 were $16.67 \%$ (22/132) and 6.82\% (9/132), respectively, and the detection rate of the co-infection was $3.03 \%$ (4/132). In contrast, using conventional PCR, the positive detection rates of FPV and FBoV-1 were $13.64 \%$ (18/132) and 5.30\% (7/132), respectively, and the co-infection rate was $1.52 \%$ (2/132). This indicates that the developed SYBR Green duplex real-time qPCR assay was more sensitive than the conventional PCR.

In this study, a conserved sequence from FPV and FBoV-1 was amplified using a SYBR Green duplex realtime qPCR assay, and different melting peak values were obtained. The melting peak values of FPV and FBoV-1 were $77.5^{\circ} \mathrm{C}$ and $86{ }^{\circ} \mathrm{C}$, respectively, and the two viruses could be easily distinguished by their specific melting temperature values. In addition, standard curves for FPV and FBoV-1 were established. The correlation coefficient of the standard curve of FPV was 0.999, and the standard formula was $y=-3.226 x+36.155$. The standard curve correlation coefficient of FBoV-1 was 0.998 , and the standard formula was $y=-3.295 x+38.133$. Detection limits of the two viruses were $2.907 \times 10^{1}$ copies $/ \mu \mathrm{L}$ and $3.836 \times 10^{1}$ copies/ $\mu \mathrm{L}$, respectively, which were 100 times higher than those of the conventional PCR method used in a previous study (Zhang et al. 2019). In addition, the positive detection rate of the SYBR Green real-time duplex qPCR assay was higher than that of the conventional PCR; the samples that were negative with conventional PCR and positive with the SYBR Green duplex real-time qPCR assay were confirmed to be positive by DNA sequencing, which indicated that the SYBR Green duplex real-time qPCR assay had a high sensitivity for detection at low viral load levels. In addition, to determine the feasibility of the assay, we carried out repeatability verification. The results showed that the intra-assay and inter-assay CVs were $0.81-1.32 \%$ for FPV and $0.15-0.89 \%$ for FBoV-1, and $1.35-1.54 \%$ for FPV and $0.39-1.71 \%$ for FBoV-1, respectively. Both sets of which were less than $2 \%$, indicating that the assay had good repeatability.

In summary, the SYBR Green-based duplex real-time PCR assay established in this study is a rapid, sensitive, and reliable laboratory testing method to detect FPV and FBoV-1 simultaneously. It is suitable for high-throughput screening of a low level of viral genome, which exhibits potential adaptability and stability for the differential diagnosis of FPV and FBoV-1 in field samples.

Supplementary Information The online version contains supplementary material available at https://doi.org/10.1007/s13205-021-02947-w.

Acknowledgements We would like to thank Editage (www.editage.cn) for English language editing.

Author contributions YP, JW, and XT were involved in performing experiments. JS, and FX were involved in data analysis, experimental design. YW, BC, and TZ wrote the manuscript. All authors read and approved the final manuscript.

Funding This study was supported by the Ningbo Health Branding Subject Fund (No. ppxk2018-10).

\section{Declarations}

Conflict of interest All authors have declared that no competing interests exist.

\section{References}

Amimo JO, Njuguna J, Machuka E, Okoth E, Djikeng A (2017) First complete genome sequences of porcine bocavirus strains from East Africa. Genome Announc. https://doi.org/10.1128/genom eA.00093-17

Barrs VR (2019) Feline panleukopenia: a re-emergent disease. Vet Clin N Am Small Anim Pract 49(4):651-670. https://doi.org/10. 1016/j.cvsm.2019.02.006

Cotmore SF, Agbandje-McKenna M, Chiorini JA, Mukha DV, Pintel DJ, Qiu J, Soderlund-Venermo M, Tattersall P, Tijssen P, Gatherer D, Davison AJ (2014) The family Parvoviridae. Arch Virol 159(5):1239-1247. https://doi.org/10.1007/s00705-013-1914-1 
Garigliany M, Gilliaux G, Jolly S, Casanova T, Bayrou C, Gommeren K, Fett T, Mauroy A, Levy E, Cassart D, Peeters D, Poncelet L, Desmecht D (2016) Feline panleukopenia virus in cerebral neurons of young and adult cats. BMC Vet Res 12:28. https://doi.org/ 10.1186/s12917-016-0657-0

Hai YP, Lee ACH, Frommer L, Diana T, Kahaly GJ (2020) Immunohistochemical analysis of human orbital tissue in Graves' orbitopathy. J Endocrinol Invest 43(2):123-137. https://doi.org/10.1007/ s40618-019-01116-4

Johnson RH, Margolis G, Kilham L (1967) Identity of feline ataxia virus with feline panleucopenia virus. Nature 214(5084):175-177. https://doi.org/10.1038/214175a0

Kailasan S, Agbandje-McKenna M, Parrish CR (2015) Parvovirus family conundrum: what makes a killer? Annu Rev Virol 2(1):425450. https://doi.org/10.1146/annurev-virology-100114-055150

Lau SKP, Woo PCY, Yeung HC, Teng JLL, Wu Y, Bai R, Fan RYY, Chan KH, Yuen KY (2012) Identification and characterization of bocaviruses in cats and dogs reveals a novel feline bocavirus and a novel genetic group of canine bocavirus. J Gen Virol 93(Pt 7):1573-1582. https://doi.org/10.1099/vir.0.042531-0

Liu C, Liu F, Li Z, Qu L, Liu D (2018) First report of feline bocavirus associated with severe enteritis of cat in Northeast China. J Vet Med Sci 80(4):731-735. https://doi.org/10.1292/jvms.17-0444

Liu L, Zhang Y, Cui P, Wang C, Zeng X, Deng G, Wang X (2019) Development of a duplex TaqMan real-time RT-PCR assay for simultaneous detection of newly emerged H5N6 influenza viruses. Virol J 16(1):119. https://doi.org/10.1186/s12985-019-1229-2

Lu G, Zhang X, Luo J, Sun Y, Xu H, Huang J, Ou J, Li S (2018) First report and genetic characterization of feline kobuvirus in diarrhoeic cats in China. Transbound Emerg Dis 65(5):1357-1363. https://doi.org/10.1111/tbed.12916

McEndaffer L, Molesan A, Erb H, Kelly K (2017) Feline panleukopenia virus is not associated with myocarditis or endomyocardial restrictive cardiomyopathy in cats. Vet Pathol 54(4):669-675. https://doi.org/10.1177/0300985817695516

Ng TF, Mesquita JR, Nascimento MS, Kondov NO, Wong W, Reuter G, Knowles NJ, Vega E, Esona MD, Deng X, Vinje J, Delwart E (2014) Feline fecal virome reveals novel and prevalent enteric viruses. Vet Microbiol 171(1-2):102-111. https://doi.org/10. 1016/j.vetmic.2014.04.005

Niu TJ, Yi SS, Wang X, Wang LH, Guo BY, Zhao LY, Zhang S, Dong H, Wang K, Hu XG (2019) Detection and genetic characterization of kobuvirus in cats: the first molecular evidence from Northeast China. Infect Genet Evol 68:58-67. https://doi.org/10.1016/j. meegid.2018.12.010

Okiro LA, Tancos MA, Nyanjom SG, Smart CD, Parker ML (2019) Comparative evaluation of LAMP, qPCR, conventional PCR, and ELISA to detect Ralstonia solanacearum in Kenyan potato fields. Plant Dis 103(5):959-965. https://doi.org/10.1094/ PDIS-03-18-0489-RE

Pfankuche VM, Jo WK, van der Vries E, Jungwirth N, Lorenzen S, Osterhaus A, Baumgartner W, Puff C (2018) Neuronal vacuolization in feline panleukopenia virus infection. Vet Pathol 55(2):294 297. https://doi.org/10.1177/0300985817738096

Piewbang C, Kasantikul T, Pringproa K, Techangamsuwan S (2019) Feline bocavirus-1 associated with outbreaks of hemorrhagic enteritis in household cats: potential first evidence of a pathological role, viral tropism and natural genetic recombination. Sci Rep 9(1):16367. https://doi.org/10.1038/s41598-019-52902-2
Sun B, Cai Y, Li Y, Li J, Liu K, Li Y, Yang Y (2013) The nonstructural protein NP1 of human bocavirus 1 induces cell cycle arrest and apoptosis in Hela cells. Virology 440(1):75-83. https://doi.org/ 10.1016/j.virol.2013.02.013

Sun Y, Cheng Y, Lin P, Zhang H, Yi L, Tong M, Cao Z, Li S, Cheng S, Wang J (2019) Simultaneous detection and differentiation of canine parvovirus and feline parvovirus by high resolution melting analysis. BMC Vet Res 15(1):141. https://doi.org/10.1186/ s12917-019-1898-5

Takano T, Takadate Y, Doki T, Hohdatsu T (2016) Genetic characterization of feline bocavirus detected in cats in Japan. Arch Virol 161(10):2825-2828. https://doi.org/10.1007/s00705-016-2972-y

Truyen U, Parrish CR (1992) Canine and feline host ranges of canine parvovirus and feline panleukopenia virus: distinct host cell tropisms of each virus in vitro and in vivo. J Virol 66(9):5399-5408. https://doi.org/10.1128/JVI.66.9.5399-5408.1992

Wang J, Lin P, Zhao H, Cheng Y, Jiang Z, Zhu H, Wu H, Cheng S (2016) Continuing evolution of canine parvovirus in China: isolation of novel variants with an Ala5Gly mutation in the VP2 protein. Infect Genet Evol 38:73-78. https://doi.org/10.1016/j. meegid.2015.12.009

Wischhusen J, Padilla F (2017) Microbubble enzyme-linked immunosorbent assay for the detection of targeted microbubbles in in vitro static binding assays. Ultrasound Med Biol 43(7):1506-1519. https://doi.org/10.1016/j.ultrasmedbio.2017.03.004

Wong YP, Othman S, Lau YL, Radu S, Chee HY (2018) Loop-mediated isothermal amplification (LAMP): a versatile technique for detection of micro-organisms. J Appl Microbiol 124(3):626-643. https://doi.org/10.1111/jam.13647

Yi S, Niu J, Wang H, Dong G, Guo Y, Dong H, Wang K, Hu G (2018a) Molecular characterization of feline astrovirus in domestic cats from Northeast China. PLoS ONE 13(10):e0205441. https://doi. org/10.1371/journal.pone.0205441

Yi S, Niu J, Wang H, Dong G, Zhao Y, Dong H, Guo Y, Wang K, Hu G (2018b) Detection and genetic characterization of feline bocavirus in Northeast China. Virol J 15(1):125. https://doi.org/10.1186/ s12985-018-1034-3

Yu Z, Zhang D, Yang K, Bai C, Li Y, Li J, Jiang S, Wang Y (2020) A simple and rapid diagnostic method to detect new goose astrovirus using reverse-transcription loop-mediated isothermal amplification. 3 Biotech 10(1):20. https://doi.org/10.1007/ s13205-019-2006-Z

Zhai SL, Lin T, Chen YW, Liu R, Lv DH, Wen XH, Zhu XL, Wang D, Li F, Wei WK (2017) First complete genome sequence of canine bocavirus 2 in mainland China. New Microbes New Infect 18:4749. https://doi.org/10.1016/j.nmni.2017.04.002

Zhang W, Li L, Deng X, Kapusinszky B, Pesavento PA, Delwart E (2014) Faecal virome of cats in an animal shelter. J Gen Virol 95(Pt 11):2553-2564. https://doi.org/10.1099/vir.0.069674-0

Zhang Q, Niu J, Yi S, Dong G, Yu D, Guo Y, Huang H, Hu G (2019) Development and application of a multiplex PCR method for the simultaneous detection and differentiation of feline panleukopenia virus, feline bocavirus, and feline astrovirus. Arch Virol 164(11):2761-2768. https://doi.org/10.1007/s00705-019-04394-8

Zou W, Cheng F, Shen W, Engelhardt JF, Yan Z, Qiu J (2016) Nonstructural protein NP1 of human bocavirus 1 plays a critical role in the expression of viral capsid proteins. J Virol 90(9):4658-4669. https://doi.org/10.1128/JVI.02964-15 